\title{
Rehabilitation of Semi-mountainous Forest Area Using Bioclimatic Forest Constructions in Greece
}

Sarantis-Angelos Liampas, Christos Stamatiou, Dimitris Farmakis, Christodoulos Daoutis, George Tasionas and Vasileios Drosos

Institute of Forest EngineeringSciences and Surveying, Department of Forestry and Management of Environment and Natural Resources, Democritus University of Thrace, Orestiada 68200, Greece

\begin{abstract}
Forest constructions are structures erected for serving the forest exploitation and utilization of its products, including recreation. The construction principals of a standard forest village with wooden lodgings apply principles of bioclimatic design and use ecological building materials. It highlights the area and helps to maintain the natural beauty of the forest. Accurate analysis of the area of the forest village requires the creation of topographic plan with great precision. Topographical drawing in AutoCAD in coordinate system HGRS' 87 with contour interval 2 meters with the help of geodetic GPS was created. The aim of this paper was the rehabilitation of a semi-mountainous area taking into consideration environmental, economic, ergonomic and architectural constrains with the help of Google Earth. The area of the camp outside the village of Dadia of Evros Prefecture was granted by the army to the Forest Office of Soufli and remains unexploited until today. The installations were recorded and shown together with the topographic diagram and an image from Google Earth for the understudy-area. All the proposed facilities are presented in a Google Earth image and in a three-dimensional view. The forest village will be composed of 20 wooden lodges with a capacity of 4 persons each. The lodges will be designed around the bioclimatic design, in order to exercise the least impact on the natural environment and to meet the needs of residents for a comfortable and relaxed living. The landscaping was based on better utilization and lower environmental cost of construction in the landscape.
\end{abstract}

Key words: Forest constructions, forest village, geodetic GPS, landscape, Google Earth, AutoCAD.

\section{Introduction}

Forest constructions are structures erected for serving the forest exploitation and utilization of its products, including recreation. The construction principals of a standard forest village with wooden lodgings apply principles of bioclimatic design and use ecological building materials. It highlights the area and helps to maintain the natural beauty of the forest.

The bioclimatic design of buildings or the bioclimatic architecture concerns the design of buildings and spaces (internal and external-outdoor) on the basis of the local climate, for the purpose of ensuring conditions of thermal and aesthetical convenience, exploiting the solar energy and other

Corresponding author: Sarantis-Angelos Liampas, Ph.D., main research fields: forest roads, forest operation, forest construction, forest opening up and forest fires. environmental sources, as well as the natural phenomena of the climate [1].

The bioclimatic architecture constitutes one of the most important factors of the sustainable build, which deals with the integration of the environmental parameters on the level of building units, studying the subsequent directions:

(a) The deliberation of the built environment and the problems it engenders (rise of temperature, concentration of gas pollutants, difficulty in air circulation);

(b) The design of buildings;

(c) The selection of the building materials, taking both their thermal and aesthetical properties and their toxicological effect into account.

The efficiency of the bioclimatic design depends on several parameters; a fact that renders it "sensitive" in exogenous and non-technical factors. For this reason, 
basic criteria for the implementation of the bioclimatic design should consist of:

- The simplicity of use in applications and the avoidance of elaborate passive systems and techniques;

- The minor contribution of building's user to the operation of systems;

- The use of widely applied systems;

- The use of techno-economical efficient energy technologies.

The design of wooden residences with bioclimatic features along with selection of suitable eco-friendly materials for these residences has been conducted.

The passive solar architecture in essence is supposed to stand for the architectural design which minimizes the effects of the weather, both in summer and winter.

The term "passive" underlines the significant difference which discerns two distinctive approaches. Solar systems which operate with the help of fans and mechanical pumps are characterized as "active". The term "passive" denotes simple technology and exploitation of energy which inheres in the specific area, in association with architectural components.

For someone to thoroughly understand the essence of the passive systems, it is important to comprehend their basic features [2].

However, it is impossible to aim at the improvement of the environment through technical interventions or measures which relate only to the own separate building, without our intervention in the wider integration; the parameters which define the relations of built-free space, the effects of the city functions, the activities which grow within the city, namely via the structure of space and the usage selected by users. It is required to assess the building in relation to urban planning, researching the consequences of the interdependences and effects, the beneficial or adverse effects of the surroundings, usages and functions, so as principles and resolutions are formulated which could contribute to the attainment of the basic aims:

- The improvement of the environment;
- The energy saving;

- The rational use and management of natural resources, ensuring tolerable living conditions, both within the building and the urban environment, corroborating the parameters which conduce to a positive interdependence among the building and the residential area, the urban space, the climate and the natural environment [3].

For the bulk of the European governments, the struggle against the greenhouse effect partly relies on the growth of the use of wood upon the construction. During the ministerial meeting for the protection of forests in Europe which was convened in Helsinki on June 1993, several scopes corresponded to the great problems were specified, so as the commitments decided at the summit meeting in Rio de Janeiro are determined:

- Sustainable exploitation of forest heritage;

- Containment of the waste upon the exploitation of wood;

- Energy assessment of biomass, so as fossil fuels are spared;

- Increasing the use of wood in the construction business [4].

The aim of this paper was the rehabilitation of a semi-mountainous area taking into consideration environmental, economic, ergonomic and architectural constrains with the help of Google Earth. The area of the camp outside the village of Dadia of Evros Prefecture was granted by the army to the Forest Office of Soufli and remains unexploited until today.

\section{Materials and Methods}

\subsection{Research Area}

The Dadia-Lefkimi-Soufli Forest National Park is situated between longitudes $26^{\circ} 01^{\prime}-26^{\circ} 19^{\prime} \mathrm{E}$ and latitudes $40^{\circ} 58^{\prime}-41^{\circ} 15^{\prime} \mathrm{N}$ in the Regional Department (Region) of East Macedonia-Thrace, in northeastern Greece. The Dadia forest is situated in a low altitude zone $(10$ to $640 \mathrm{~m})$, the natural vegetation of which belongs, according to Dafis, S. A. in 1973 [5], mainly 
to the sub-zone of xerophilous deciduous oaks (Quercionconfertae) of the para-Mediterranean zone (Quercetalia pubescentis). Access to the area of the camp outside the village of Dadia of Evros Prefecture, almost the center of the park is along a $6.5 \mathrm{~km}$ local road of the No. 51 national road (Alexandroupoli-Orestiada).

\subsection{Methodology}

Accurate analysis of the area of the forest village requires the creation of topographic plan with great precision. Topographical drawing in AutoCAD in coordinate system HGRS' 87 with contour interval 2 meters with the help of geodetic GPS was created.

For the design of the residences, it has been assumed that the inhabitants will be static in the interior; that is to say they will not carry out any arduous work.

The best orientation of the residences for the optimum exploitation of the sun is the south-eastern, very close to the south one.

The creation of a technical design, the designing as a conception, has always been and is a constituent part of an engineer's work. A technical project is conceived and initially attributed on paper as a technical design, and subsequently, is constructed by accurately following the instructions which are also depicted on paper in the form of technical design. The technical design should not leave obscurities regarding the building project which is to be constructed and should be carefully performed, discernible, clean, without imperfections and with resistance upon wear and time.

The AutoCAD of the Autodesk Company is one of the best for forest engineering applications which are available on the market, the most widespread and is of general purpose, to wit, can be applied to architecture, statics, topography, hydraulics, road construction and generally to every forest engineering field.

\section{Results}

The installations were recorded and shown together with the topographic diagram and an image from Google earth for the study area. All the proposed facilities are presented in a Google Earth image and in a three-dimensional view (Table 1, Fig. 1).

The forest village will be composed of 20 wooden lodges with a capacity of 4 persons each. The lodges will be designed around the bioclimatic design, in order to exercise the least impact on the natural environment and to meet the needs of residents for a comfortable and relaxed living. The landscaping was based on better utilization and lower environmental cost of the construction in the landscape (Fig. 2).

Fig. 3 shows the proposal layout for the configuration of the area by placing the buildings, the parking area, the recreation area and tree planting in points needed:

- Gray is the road;

- The blue line defines the recreation area;

- With yellow are the buildings that are placed in two;

- With brown are the paths that will start from the car park and end up in the buildings;

- Dark green is the old buildings that will be demolished and to their existing outline to build flower beds that will remind the previous use of the area;

- With light green are trees to be planted;

- The parking area is nearby the recreation area.

Table 1 Points that encompass the region of study.

\begin{tabular}{lll}
\hline School & East & North \\
\hline 1 & 686026.066 & 4554349.882 \\
2 & 686163.166 & 4554683.765 \\
3 & 686253.073 & 4554717.186 \\
4 & 686430.736 & 4554828.900 \\
5 & 686479.645 & 4554817.956 \\
6 & 686577.351 & 4554563.018 \\
7 & 686581.446 & 4554511.479 \\
8 & 686553.521 & 4554448.725 \\
9 & 686551.119 & 4554422.481 \\
10 & 686478.115 & 4554359.347 \\
11 & 686365.001 & 4554365.319 \\
12 & 686188.378 & 4554313.753 \\
\hline
\end{tabular}




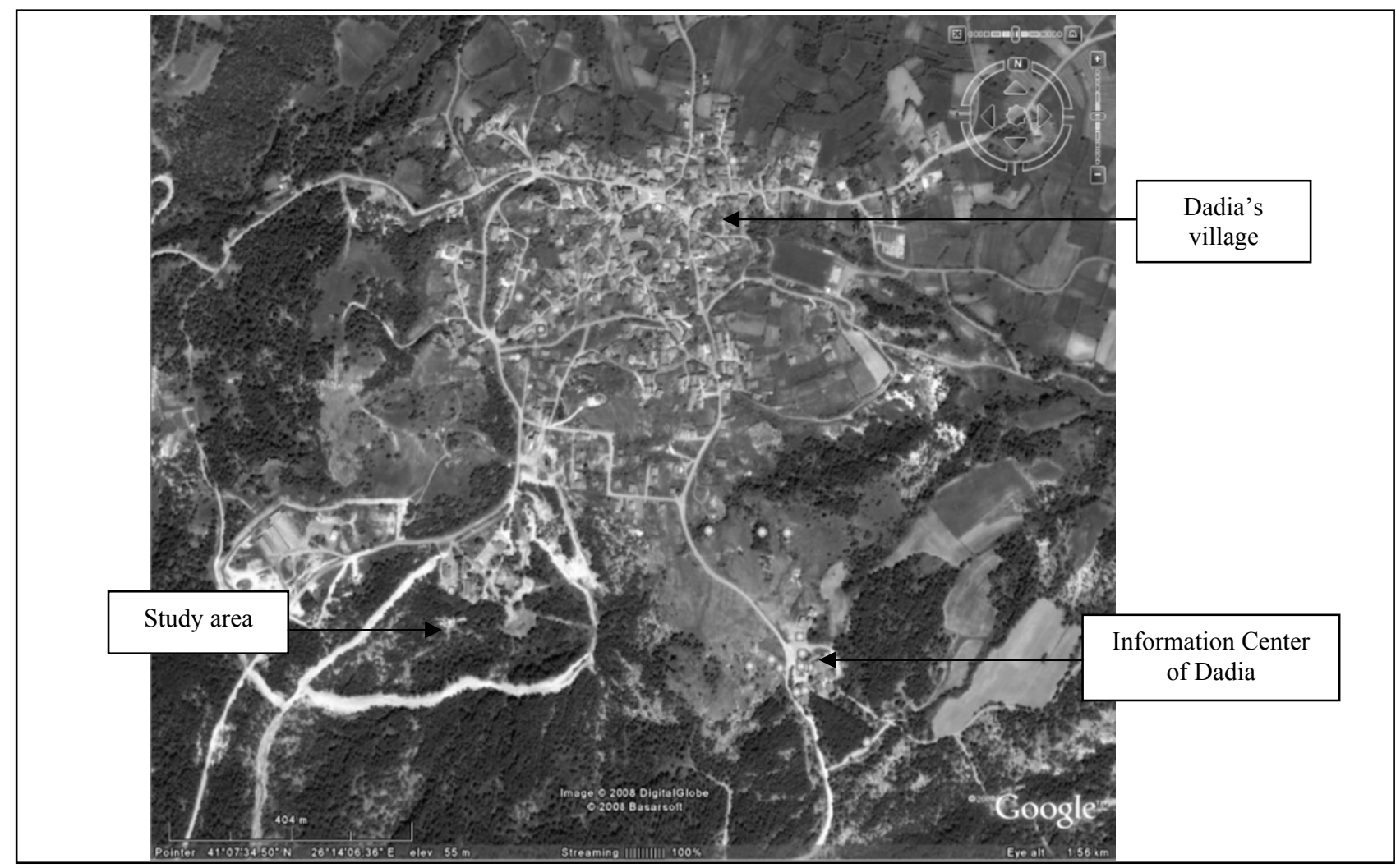

Fig. 1 Picture from the Google Earth for the region of Dadia.

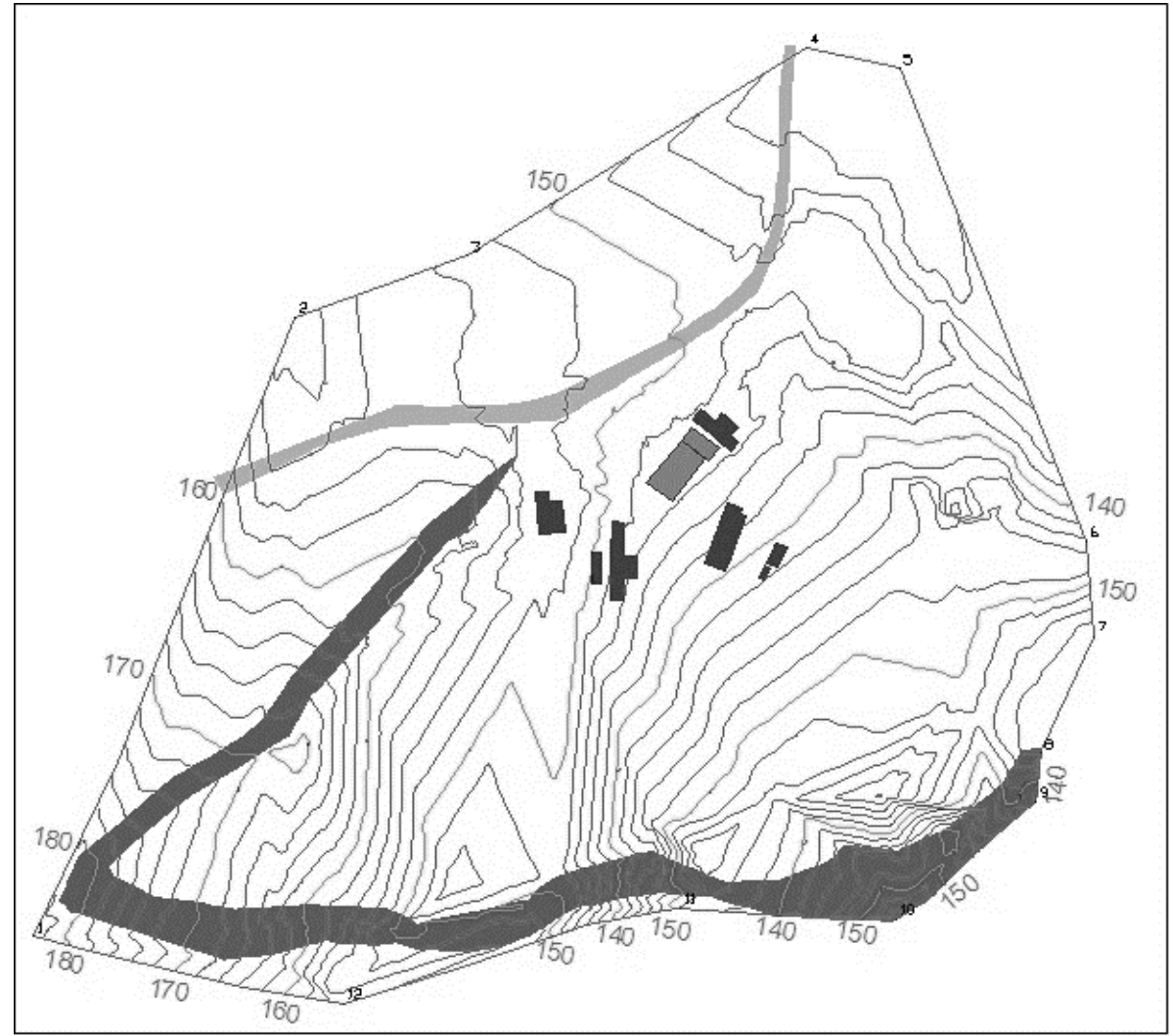

Fig. 2 Topographic diagram of the region. 


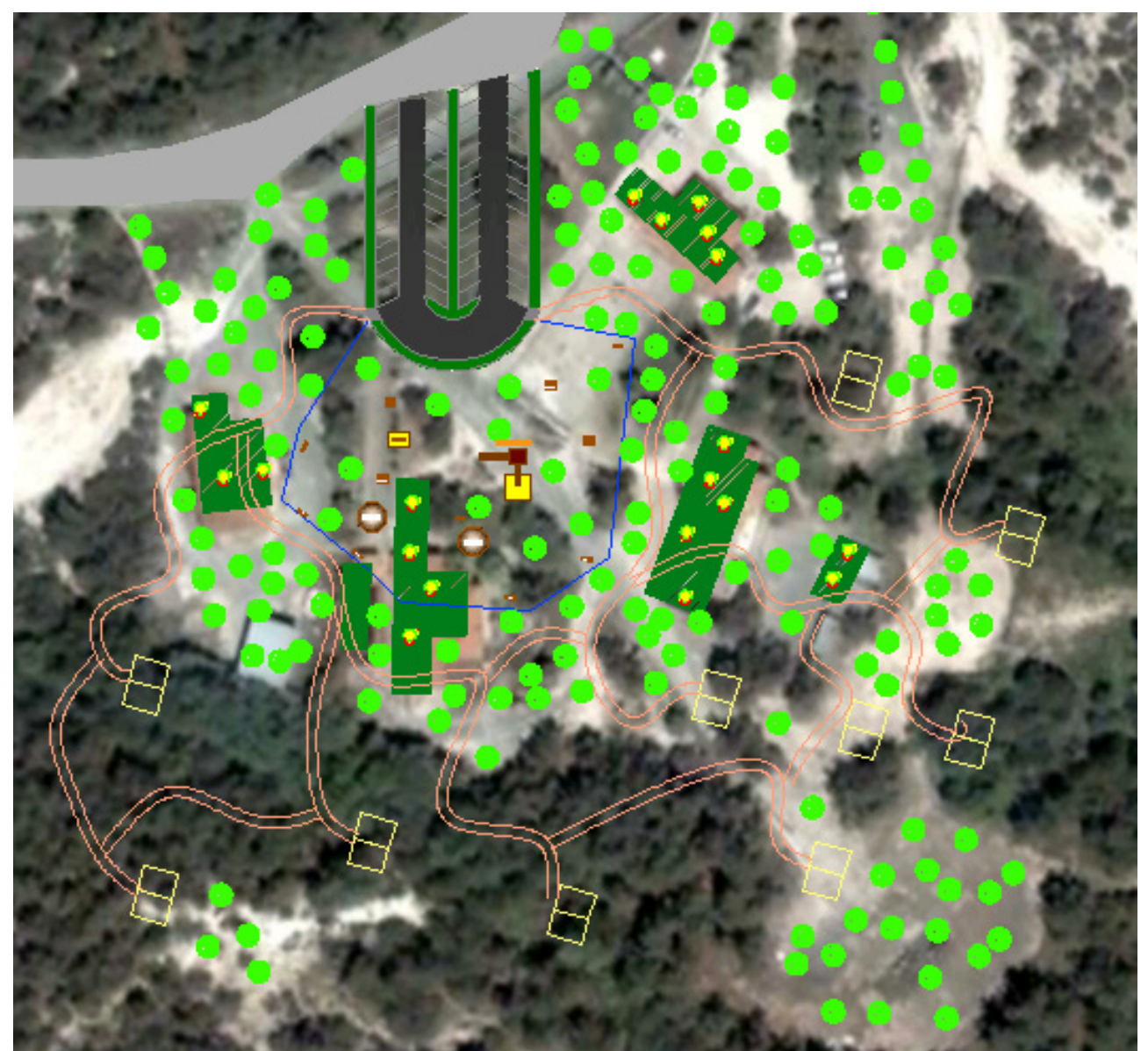

Fig. 3 Picture from the Google Earth with the new configuration.

\section{Analysis and Discussion}

The area of the camp outside the village of Dadia of Prefecture Evros granted by the army in Forest Office of Soufliou remains untapped till today. Due to the growing development of the village of Dadia and due to the rare birds of prey, it is proposed to construct a forest village based on bioclimatic design.

The forest recreation area that is studying because it is going to be used to rest and relaxation the modern man, must offer a very good level of accommodation for visitors with all the comforts of modern times. The specific area for the creation of the forest village is chosen for the double goal that is achieved by its exploitation. On the other hand, there is the rehabilitation of a disturbed area and, on the other hand, the need to host more and more visitors in the forest of Dadia.
For the development of mountain tourism better siting for the necessary accommodation could not exist from the mountain villages. There are basic infrastructures (road access, electricity, water supply and telecommunications). Visitors to the mountainous regions, alongside the acquaintance with nature, also want to get familiarized with the local communities (manners and customs, linguistic idioms, local cuisine, etc.). Every natural sight of the mountainous region can be approached by the visitor in a very short time, based on the mountain villages. There is no reason to cause interventions in the heart of the natural environment with new infrastructure (roads, electricity-water supply networks, telecommunication lines and antennas) which in any case have smaller or greater impact on the environment and degrading the landscape.

The choice of this location does not contradict the above because it is very close to the village of Dadia. 
The need for a further road network does not exist as there is already an asphalt road until the entrance of the proposed forest village. No further basic infrastructures (electricity, water supply, telecommunications) are needed because of the site was formerly used and these are exist but need modernization. The forest village is not in danger of forest fires due to the pre-existing buffer zone that protected the camp.

In the village, there is a private 20 -bed guest house and the Dadia information center can accommodate guests. The construction of the forest village does not operate competitively with the existing facilities; on the contrary, it enhances the possibility to accommodate more visitors in the village of Dadia. The construction of the forest village will allow visitors to have the village of Dadia as their base, thus allowing more visitors to stay longer in the village of Dadia than a simple visit to the wildlife information center. More time in order to explore wildlife and getting acquainted with the local community has the visitors, achieving economic development of the village through agrotourism.

During the planning of the forest village, apart from the bioclimatic design of the buildings, attention was paid to the restoration of the landscape. Existing houses are proposed to be demolished and to their existing outline to build flower beds that will contain shrubs, trees and flowers. A building, when demolished, dies, but with the above rehabilitation design helps to keep these buildings monuments that betray the previous use of the area. In the rest of the area, it is proposed to planting with native species in order to have the best possible landscape restoration. A part of the camp will become a parking area for the visitors' vehicles and next to it will be a delimited recreation area with kiosks (gazebos), barbecues, playground, etc. Access to the buildings will become a network of paths that starts from the parking area and will not exceed 5 minutes walking. The buildings provide all the modern amenities and there is no need to create a large central building that would not fit with the environment.

The removal of some trees is necessary for the installation of the buildings and their surrounding area, but it is compensated by the tree planting of most of the camp. The buildings were placed in such manner within the study area so that the visitor can find the peace and quiet he is looking for, but on the other hand, he does not feel cut off from the whole. Glades and open spaces were preferred for the placement of the buildings in order to minimize the removal of trees and vegetation. The slope of the paths in the area is mild, so that it does not cause fatigue but a pleasant walk through the forest to the house. Marking and demarcation with wooden rails of the paths is very important for facilitating access to the buildings. The configuration of the surrounding area of the buildings is very important for the operation of their bioclimatic characteristics, which is also the purpose of the study.

The buildings in the forest village were constructed according to the principles of bioclimatic design. Wood was used to build them as recyclable natural material. For the heating of the rooms, the use of the fireplace was preferred. Outside the roof of the houses was constructed in such a way that in the winter when the sun is lower, it is easier to heat the houses, and on the other side, in the summer when the sun is upper, to prevent the entrance so be cool and not need other means for cooling.

\section{Conclusion}

For the wider area of the forest village, it is recommended: restoration of the vegetation to the west of the camp that served as a parking area for military vehicles, improvement of the road network to the village of Dadia, creation of information material for all visited places of the area.

The building or construction of forest engineering works should be pursued: the simple and elegant construction but economically advantageous, because 
every luxury in its appearance is expensive and unusual for the intended purpose. With the building or construction of forest engineering projects should be pursued: the simple and elegant construction, but cost-effective, because every luxury in appearance is costly and ineffective for its intended purpose.

\section{References}

[1] CRES (Centre for Renewable Energy). 2002. Operational Programme for Energy, Bioclimatic Design in Greece, Energy Efficiency and Guidelines for Implementation.
Athens: Pikermi, 1-51.

[2] Colombo, R., Landabaso, A., and Sevilla, A. 1995. Manual Design, Passive Solar Architecture for the Mediterranean Region. Joint Research Centre, European Commission, Institute for Systems Engineering and Informatics, 15-45.

[3] Gauzin-Muller, D. 2003. Ecological Architecture. Thessaloniki: Ktirio Publications, 45.

[4] Tsipiras, S. K., and Tsipiras, S. T. 2005. Ecological Architecture. Athens: Kedros Publications, 34.

[5] Dafis, S. A. 1973. "Classification of the Forest Vegetation of Greece." In Scientific Annals of the Agronomy and Forestry School, 75-86. 